\title{
Some Early Travails of Tracing Axonal Pathways in the Brain
}

\author{
Walle J. H. Nauta \\ Department of Brain and Cognitive Sciences, Massachusetts Institute of Technology, Cambridge, Massachusetts 02139
}

The first great flowering of neuroanatomy began about 1870 , reached its height in the late 1880 s and, with some notable exceptions, went into a marked decline during the two decades between the first and the second World Wars. In this essay I will relate some of my personal experiences during the early stages of a second flowering of neuroanatomy that began some fifty years ago and ultimately led to the multifaceted neuroanatomy we now know.

My account begins in 1937, when I had just passed the preclinical examinations at the University of Leiden, and had accepted a two-year student assistantship in the anatomy department. A student assistantship was a formidable commitment of time and effort, but it also, in addition to free tuition, provided a valuable fringe benefit: student assistants had access to the histology laboratory and, after receiving basic instruction in histological technique, were allowed to take on a research project of their own. I chose to acquaint myself with the rat brain, as it appeared in serial paraffin sections that I had staincd altcrnately with toluidine blue for cell bodies and with the protargol staining method for nerve fibers published by David Bodian (1936) only the year before. The Bodian method was a great boon to neuroanatomy: it was the first technique to permit excellent, routine silver staining of nerve fibers in paraffin sections. That was a particular blessing to me, for paraffin sections were the only type of sections I then knew how to cut and handle.

It should be mentioned here that the anatomy of the brain was not a popular research topic in the 1930s. In Europe, at least, the subject was widely regarded as already harvested to exhaustion, and hence hardly worth exploring further. The term "neuroanatomy" did not even exist; the subject was considered to be simply part of general anatomy. It was pursued as an active research subject in only a few anatomy departments, of which Leiden's was not one.

While slowly becoming better acquainted with the rat brain, I developed a particular interest in the hypothalamus. The literature appearing at that time provided ample reason for such an interest. The first publications of the Scharrers had just come out, reporting their astonishing observation that cells of the magnocellular nuclei of the hypothalamus combine neural with secretory characteristics. The laboratories of S. W. Ranson in Chicago and W. R. Hess in Zurich were reporting a steady stream

\section{Key words: axon denervation, Nauta-Gygax method, Fink- Heimer methods, historical aspects}

Correspondence should be addressed to Walle J. H. Nauta, Department of Brain and Cognitive Sciences, Massachusetts Institute of Technology, E25-618, 77 Massachusetts Avenue, Cambridge, MA 02139.

Copyright (C) 1993 Society for Neuroscience $0270-6474 / 93 / 131337-09 \$ 05.00 / 0$ of intriguing novel findings about the involvement of the hypothalamus in autonomic and endocrine functions, as well as in the sleep-wakefulness cycle. I had also read with admiration Philip Bard's classical paper on "sham rage," a phenomenon clearly implicating the hypothalamus in at least the outward manifestations of anger. And from G. B. Wislocki's laboratories at Harvard had come evidence that the long-sought last link in the efferent pathway connecting the hypothalamus with the anterior pituitary was vascular rather than neural. I thought that these recent findings provided a good reason for an expanded search for the intrinsic and extrinsic fiber connections of the hypothalamus. It seemed to me, moreover, that several of the recent physiological findings were raising anatomical questions that could not be answered in terms of existing anatomical knowledge. And that realization, in turn, led me to think that the anatomy of the brain was a neglected rather than an exhausted subject.

It was not long, howcver, before it dawned on me that for tracing complex fiber pathways, the histological methods with which I had now become familiar would not be enough. Bodianstained sections might show fibers entering the supraoptic nucleus from the dorsal side, but when one tried to trace those fibers back to their source one would either lose them in the dense hypothalamic fiber plexus or see them exit from the section. This was an ancient experience even then, and the very reason why, more than fifty years earlier, Vittorio Marchi had introduced his ingenious strategy of tracing nerve fibers by marking them with the anterograde myelin-sheath degeneration induced by severing the fibers from their cells of origin (Marchi and Algeri, 1885). The Marchi method, I thought, ought to be able to provide the answer to questions about the destination of the efferent pathways of any brain structure.

But before I could put that belief to the test, my time in the anatomy dcpartment was up; I passed the much-dreaded clinical examination, and immediately afterward had to begin a 14 month rotating internship. An infinitely greater obstacle to the pursuit of my project was that four months later, in May of 1940, Hitler's armies launched their offensive in the West that in a matter of weeks would secure Germany's full control of the Atlantic coast of the European continent. Holland was overrun after only five days of fighting, and for the next five years had to endure Nazi occupation.

I could not return to my project until two years later, in 1942 , when $I$ had at long last completed the rotating internship and had accepted an instructorship in anatomy at the University of Utrecht. (I could not remain in Leiden because its university had been closed by the Nazi authorities a few months earlier, after repeated warnings and accusations that it was "a hornet's nest of ideological subversion.") 
Figure 1. Top, Low-power view of a frontal section through the pretectal region of a rat killed $3 \mathrm{~d}$ after enucleation of the right eye. Paraffin section, silverimpregnated by Bodian's (1936) protargol method. On the left side note the oval cluster of heavily stained neuropil in area labeled l.c.n. Bottom, Detail of area l.c.n., viewed at higher power. In and among nests of hyperargyrophilic neuropil, numerous solid club-shaped axon terminals appear. From Nauta and van Straaten (1947), courtesy of Cambridge University Press.
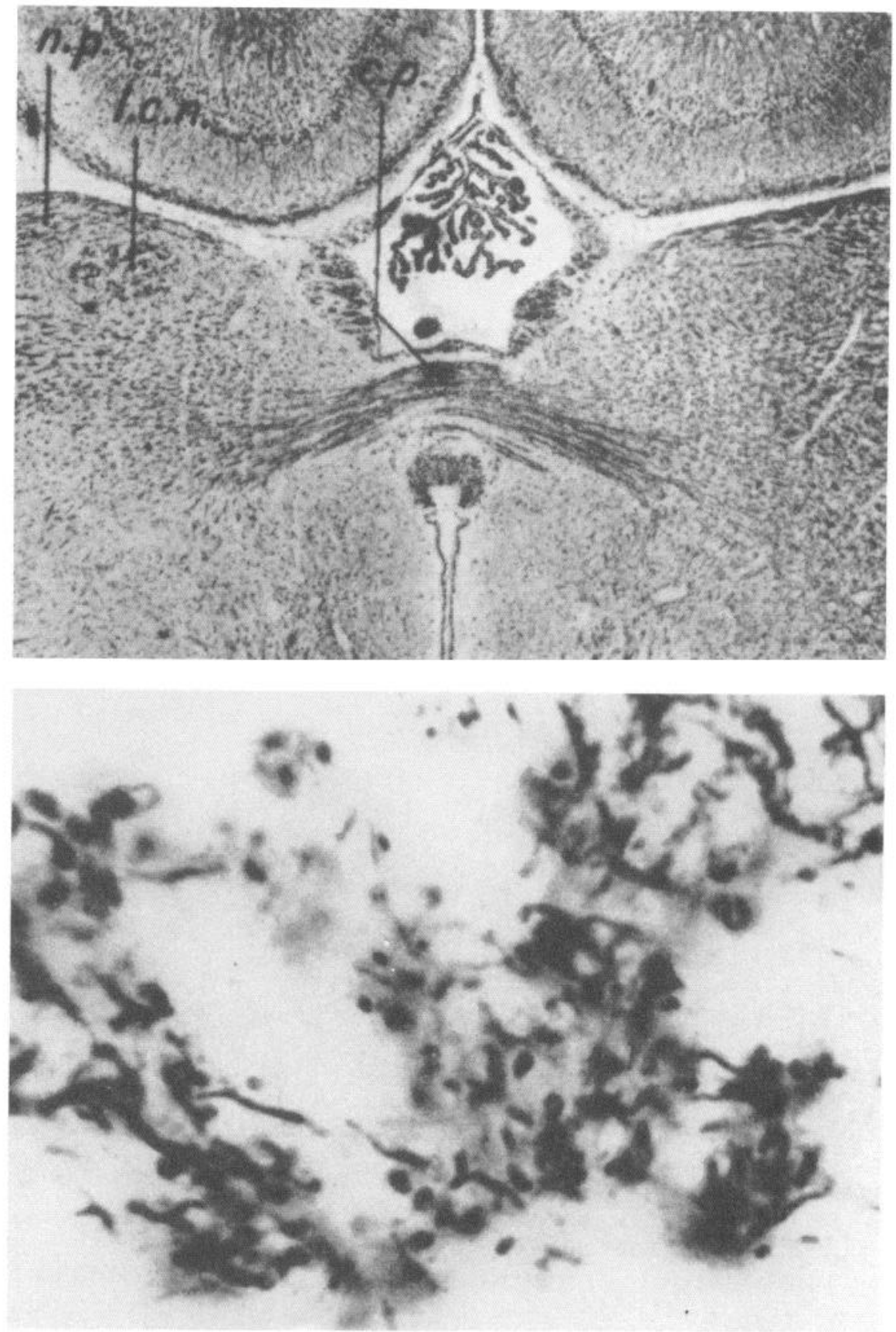

In Utrecht, thanks to the generous hospitality of the pharmacology department, I finally had a chance to place lesions in rat brains and try my luck with the Marchi method. And to my distress, in the course of that first year in Utrecht, the high hopes with which I had started out steadily faded. Although I could easily follow large numbers of degenerating fibers away from lesions placed in the cerebral cortex or thalamus, only few such fibers showed up around lesions placed in the hypothalamus. Ignorance had been the basis of my disappointed hopes: I had never examined rat brain sections stained for myelin, and so had never realized how sparsely myelinated the hypothalamic fiber plexus is.

It had now become clear to me why the Marchi method had been used so rarely in anatomical studies of the hypothalamus.
Obviously, what was needed for tracing hypothalamic fiber connections was a technique that could provide a direct image of the degenerating axon itself, rather than only of its decomposing myelin sheath.

At that point I remembered having come across a reference to a histological method that might reveal degenerating axons directly. That recollection led me to a report published in 1925 in Virchow's Archiv in which the Leningrad neuropathologist J. Rasdolsky described an elaborate staining procedure, the final steps of which stained normal nerve fibers a grayish green with the dyestuff light green, and degenerating fibers, including their terminals, a bright red or violet with fuchsin B. With high expectations, I tried the Rasdolsky method, but to my disappointment had no success with it whatever. In the hundreds of sec- 
tions I stained with this cumbersome procedure I saw only grayish bundles of normal fibers, and never glimpsed a redstained degenerating fiber. After several months of persistent failure I decided that another technique for revealing axon degeneration was needed, and that I probably would have to develop it myself.

The more I thought about the type of staining method on which I should concentrate my efforts-organic dyestuff adsorption or metallic tissue impregnation - the likelier it seemed to me that some modification of an already existing silver impregnation method would be the answer. After all, with the exception of the capricious methylene blue staining, silver impregnation thus far had been the only technique capable of providing positive images of axons in tissue sections. And, if Marchi had succeeded in modifying the osmium staining of normal myelin so that it became a selective indicator of degenerating myelin, might there perhaps exist some histochemical difference between normal and degenerating axons that could make a second Marchi-type miracle possible? Or so I wishfully argued, as yet without a clue as to where to begin my search.

While I was still pondering how to proceed, our laboratory supply house sent us a list of items that it could no longer provide, presumably until war's end. Since the list included not only all silver compounds but also such crucial histological necessities as alcohols, xylene, glass slides, and coverslips, all my plans had to be shelved. As events unfolded from here, I did not get back to the "axon-Marchi" project until nearly three years later, in early 1946, when the war had ended and I had returned to the anatomy department at the University of Leiden.

The year 1946 was one of high tension and near chaos at Leiden, as our teaching program had to accommodate not only the regular student enrollment but also a stream of "returnees"-older students who had lived in hiding for all or part of the war for reasons ranging from involvement in resistance activities to being Jewish, or simply trying to avoid conscription for forced labor by the enemy. Among these returnees was a contentious young fellow who introduced himself to me as Hans Kuypers when I first met him in the dissection laboratory, and who later became one of my cherished colleagues and friends.

Although the year 1946 was one of constant effort to keep the teaching program on track, I did get some staining experiments started, and in one of them I found to my excitement that in rats deprived of one eye and killed 3-5 d after the operation, both the Bodian method and Cajal's block-impregnation technique stained a multitude of swollen ring- and club-shaped structures amid a heavily argyrophilic neuropil in the contralateral retinoceptive cell groups (Fig. 1).

Ring-shaped argyrophilic structures had been noted in brain tissue since 1904, when the neurofibrillar silver-staining methods of Cajal and Bielschowsky were introduced (Fig. 2). Cajal (1909) had interpreted the rings as terminal loops of single or bundled neurofibrils. Neither his nor Bielschowsky's method revealed the axoplasmic end-structure in which the neurofibrillar loop was presumably enclosed. Cajal (1909) nonetheless proposed that the neurofibrillar end-ring might be a particular version of the more expansive neurofibrillar network pervading the larger axon terminals that had been discovered some ten years earlier in Golgi preparations and iron-hematoxylin-stained sections of the spinal cord and brainstem, and had been called "end-feet" by Held (1897) and "end-knobs" by Auerbach (1899). (Both names were eventually superseded by Cajal's term boutons terminaux.) That the argyrophilic ringlets were-or at least

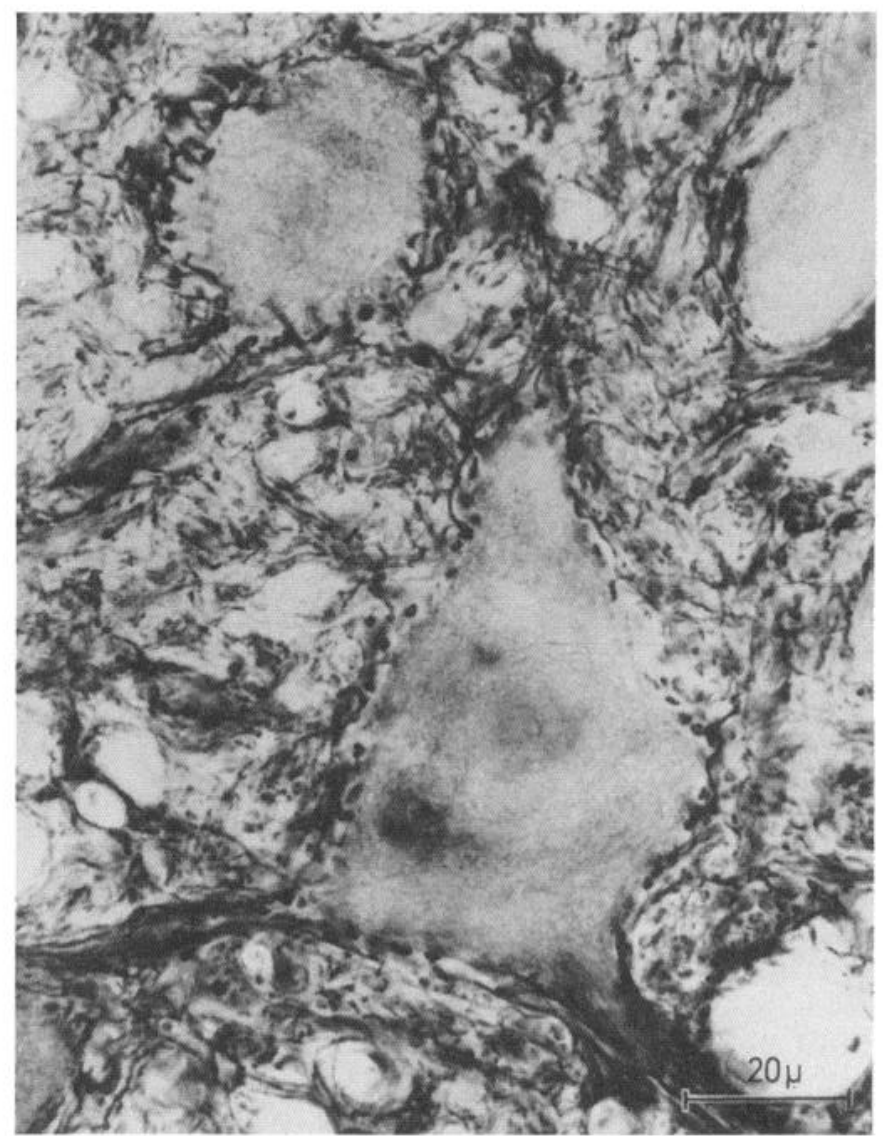

Figure 2. Cells from the base of the dorsal horn of the cat's lumbar spinal cord. Note the neurofibrillar rings and clubs covering the surface of the neuronal cell body at lower center, and of large dendrite in upper left corner of figure. Tissue stained with Barr's (1939) modification of Cajal's block-impregnation method by A. D. Loewy. From Guillery (1970), courtesy of Springer Verlag (New York).

marked-axon terminals had become widely accepted after E. C. Hoff (1932) reported finding numerous swollen rings and solid clubs in the spinal dorsal horn after dorsal root transection. Hoff's finding, suggesting that the boutons terminaux of degenerating axons are marked in silver-stained preparations by swollen end-rings, was confirmed by Gibson (1937), but the reliability of the "bouton method" as a means of determining the ultimate distribution of degenerating fibers was put into question after Phalen and Davenport (1937), Barr (1939), and Minckler (1940) reported considerable variability in the size and shape of end-rings in the normal spinal cord of various vertebrate species. Presumably as a result of these reports, the "bouton method" fell in disuse after 1940. It is noteworthy that the method had been applied exclusively to fiber systems afferent to the spinal cord, and that in doubting its validity, no account was taken of the much stricter criteria for bouton degeneration applied by Szentágothai in a series of three classical studies dealing with dorsal root and descending afferents to the spinal cord (Schimert, 1938, 1939; Szentágothai-Schimert, 1941). In these studies, using the Gros modification of the Bielschowsky method, Szentágothai disregarded mere differences in size and shape, and counted as degenerating only those axon terminals that had a spongy appearance and were attached to a terminal axon branch exhibiting varicosity and/or fragmentation as evidence of Wallerian degeneration. 
The Bielschowsky-Gros method, as used by Szentágothai, appears in retrospect as the light microscopic forerunner of the electron microscopic identification of degenerating axon terminals that was introduced some twenty years later. However, since the method seemed unsuitable for my own purpose of long-distance tracing of degenerating axons, I mistakenly paid it scant attention.

To return to my observation of swollen end-rings after unilateral eye enucleation, the fact that they appeared predominantly in the contralateral retinoceptive cell groups scemcd to leave little doubt that they indeed signaled degeneration of retinofugal axons. My initial hope, however, that the Bodian and the Cajal block-impregnation methods, which had produced these results, could be used for tracing degenerating axons was soon tempered when I could find no such changes in the known termination areas of some other degenerating fiber systems. For example, no darkened neuropil, or even end-rings of any sort, appeared in the septum or mammillary body following lesions that transected the fornix. Nor could I find such changes in the cerebral cortex after lesions of the thalamus. My optimism dwindled further when I realized that in my eye enucleation material the axons of the optic tract showed no signs of Wallerian degeneration, even though they had to be the parent fibers of the degenerating boutons in the primary visual cell groups. Rather, postoperatively these fibers seemed gradually to lose their argyrophilia; at no time did they cxhibit a positive picture of axon disintegration. Puzzled by these discrepancies, I concluded that none of the silver methods thus far used to determine the distribution of degenerating axons actually stained degenerating axoplasm. What they did stain had to be the neurofibrillar element, preferentially its expansion into the axon terminals. And since that neurofibrillar element appeared to be either sparse or absent in some other fiber systems, such as the fornix, I decided that what was needed was a method that could reveal axoplasmic degeneration, not only in terminals but throughout the course of their parent axons as well.

At the time, the mid-1940s, electron microscopy of the central nervous system still lay ten years in the future. It was not generally recognized then that the crucial details of synaptic morphology, and especially the identity of the postsynaptic element, lie beyond the reach of light microscopic technology. For instance, Cajal, in a posthumous chapter on the ncuron doctrine that appeared as late as 1935 in the Handbuch der Neurologie, expressed great uncertainty concerning the existence of boutons terminaux in the cerebral cortex. His doubts were based on the failure of both his own staining technique and the Golgi method to reveal in cortical tissue the ring- or club-shaped end-formations so commonly seen in many subcortical structures (see also comments by Dempsey, 1957, on this subject).

Concepts about the morphology of axon terminals rapidly changed after electron microscopy in the late 1950s began to show the true structure and distribution of synaptic contacts. It is now firmly established that, exactly as proposed by Cajal fifty years earlier, the argyrophilic end-rings are loop-shaped endstretches of microfilamentous bundles, that such neurofibrillar loops are by no means a standard feature of all fiber systems and are, for example, very sparse in the cerebral cortex, and, most surprising of all, that they are not invariably located within axon terminals and may occur in other parts of the neuron (Guillery, 1970).

The next phase of my benighted search for an "axoplasmic
Marchi" method was set at the anatomy department of the University of Zurich, to which I moved in 1947 for what was meant to be two years but luckily stretched to four.

Through most of my first year in Zurich I persisted in working with the Bodian and the Cajal block-impregnation methods, trying an ever-growing variety of fixatives and other chemical tissue pretreatments. All that labor got me nowhere, and I was about to give up the project when I came across a recent article in the Journal of Neuropathology and Experimental Neurology in which Paul Glees (1946), then at Oxford, described a modification of the Bielschowsky method that stained degenerating axon terminals, not as rings but as solid blobs. The illustrations of Glees' report suggested that his method also showed Wallerian degeneration of more proximal parts of the axon, but it was not clear whether the method would permit the tracing of axons over their full length. I tried the Glees method, but to my disappointment found that $I$ could not make it work. The explanation for my failure may have been simple: the Glees method explicitly called for tap water rather than distilled water to make up the $10 \%$ formalin that served as the final reducing agent, and it is possible that the tap water in Zurich differed in some crucial respect from that in Oxford and Oslo, the two cities where the Glees method eventually found its widest successful use.

Even though I could not make his method work, Glees' report had convinced me that the Bielschowsky method offered better prospects than did the Cajal-type methods I had been using up to that time. The principles underlying the Cajal and Bielschowsky procedures differ in important respects. In the Cajal process the final blackening of nerve fibers (in photographic terms, the change from the latent to the visible image by action of the developer) is produced by nascent silver released from the stable salt silver nitrate by a strong reducing agent such as hydroquinone. In the Bielschowsky process, by contrast, the nascent silver is released from a much more labile silver double salt, silver-ammonia nitrate, by a weak reducing agent, formaldehyde. Comparing the two processes, it now seemed likely to me that the latter one offered the wider opportunity for the sort of fine adjustments that might eventually lead to a method for staining degenerating axons.

In trying to master the original Bielschowsky method, however, I ran into a problem that already had bothered me in my attempts to use the Glees method: as I transferred my sections from the silver-ammonia nitrate solution to the prescribed $10 \%$ formalin reducer, they instantly turned an opaque grayish brown, thus obscuring any clear distinction of microscopic detail. Attempts to slow down the release of nascent silver by diluting the reducer and increasing its alcohol content brought little if any improvement.

My results with the Bielschowsky method took a turn for the better after I met Paul André Gygax, a doctoral student of chemical engineering at the Federal Institute of Technology in Zurich. Unlike several other chemists whom I had approached earlier, Gygax was immediately challenged when I explained my problem to him. From a survey of the literature on silver double salts, he suggested using sodium hydroxide, in addition to ammonia, in preparing the silver-ammonia nitrate solution. It was an ingenious idea: the weak base, ammonia, suppresses the dissociation of the double salt, whereas the strong base, sodium hydroxide, promotes it. By adjusting the relative concentrations of the two bases, we could now control the rate of release of nascent silver to some extent at least. The best sections we thus 

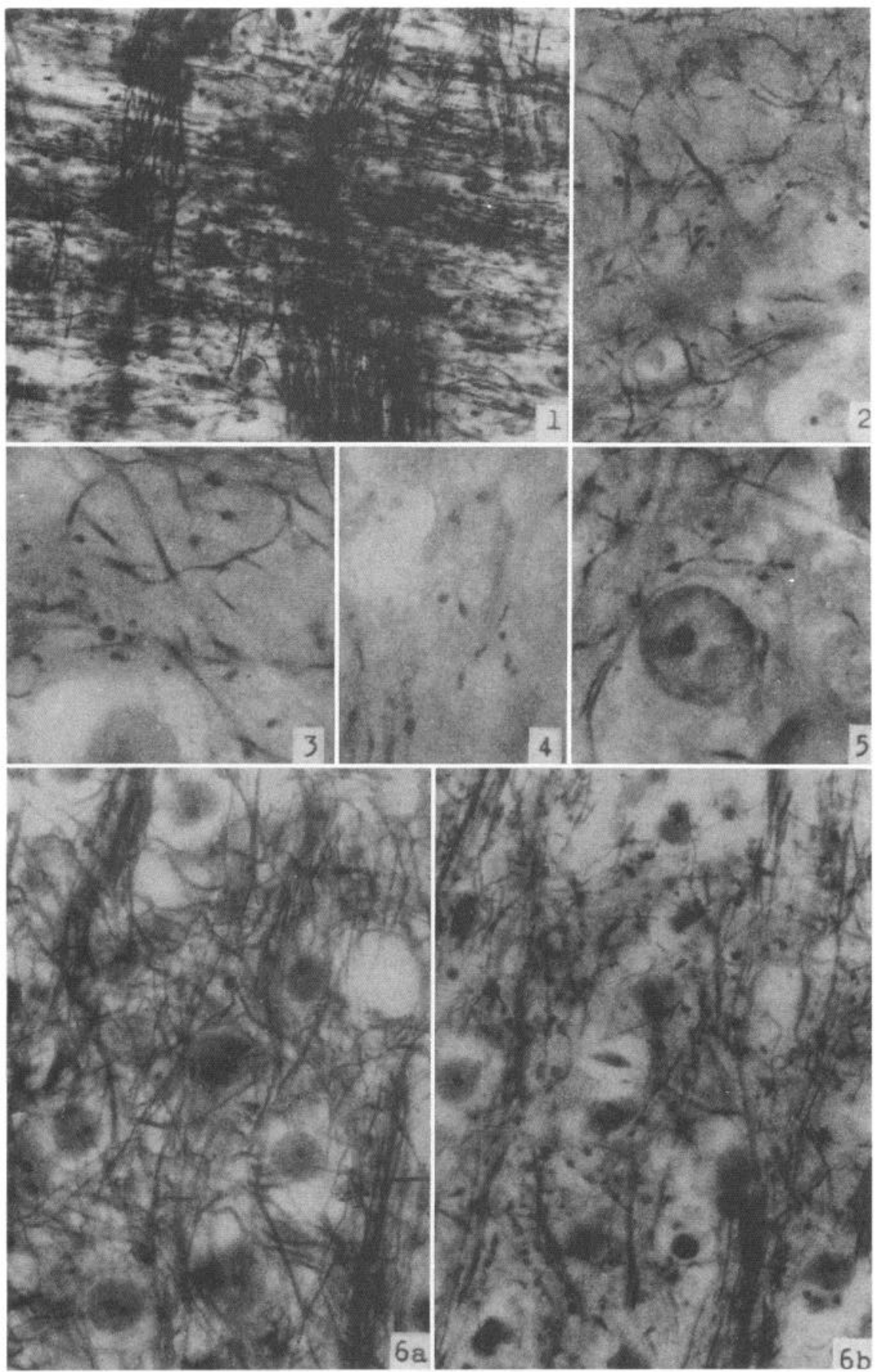

Figure 3. Axon degeneration as appearing in frozen-cut sections stained by the original, nonsuppressive NautaGygax method (1951). Panel I shows the anteroventral thalamic nucleus exhibiting massive fiber degeneration in the (here horizontally oriented) septothalamic tract of Vogt (1898) in a rat killed $3 \mathrm{~d}$ following lesion of the supracommissural septum and fornix column. Note the bundles of normal internal capsule fibers crossing the degenerating tract at nearly right angles. Panels 2-5, from same specimen as panel 1 , show terminal axon degeneration in the anteromedial thalamic nucleus (2), medial hypothalamus (3), periventricular hypothalamus (4), and nucleus accumbens (5). Panels $6 a$ and $6 b$ show, respectively, left and right frontal cortex (largely layer IV) of a rat killed $4 \mathrm{~d}$ after receiving a large lesion of the right thalamus and internal capsule. From Nauta and Gygax (1951), courtesy of Williams and Wilkins (Baltimore, MD). produced were sufficiently transparent to provide encouraging glimpses of degenerating fibers among the multitude of normal fibers. Even these sections were not clear enough, however, to allow tracing of degenerating fibers along their entire length.

After months of frustrating attempts to improve the clarity of the sections, the resolution of the problem finally materialized, suddenly and quite by accident. On a Saturday afternoon in the spring of 1949 , I discovered that I had used up all of my fresh formalin and had to make up the reducing solution from a half-empty, cork-stoppered bottle of $10 \%$ formalin that I found in an out-of-the-way place, where it had been stored for at least six years. In the reducer made up from this stale formalin the sections to my astonishment slowly turned light brown, and when I examined them in the microscope I saw, for the first time in all those years, a picture of axon degeneration that resembled the one I had been hoping for. I excitedly called Paul Gygax, who arrived a short time later, carrying a fresh supply of formalin and a small bottle of formic acid; it had not taken him more than a minute to figure out that the stale formalin I had mentioned must have had a high concentration of formic acid. A few quick trials with fresh formalin acidified with formic acid bore him out.

With this denouement, the project changed from a series of frustrations to a joyride, which, within a few weeks, ended with 

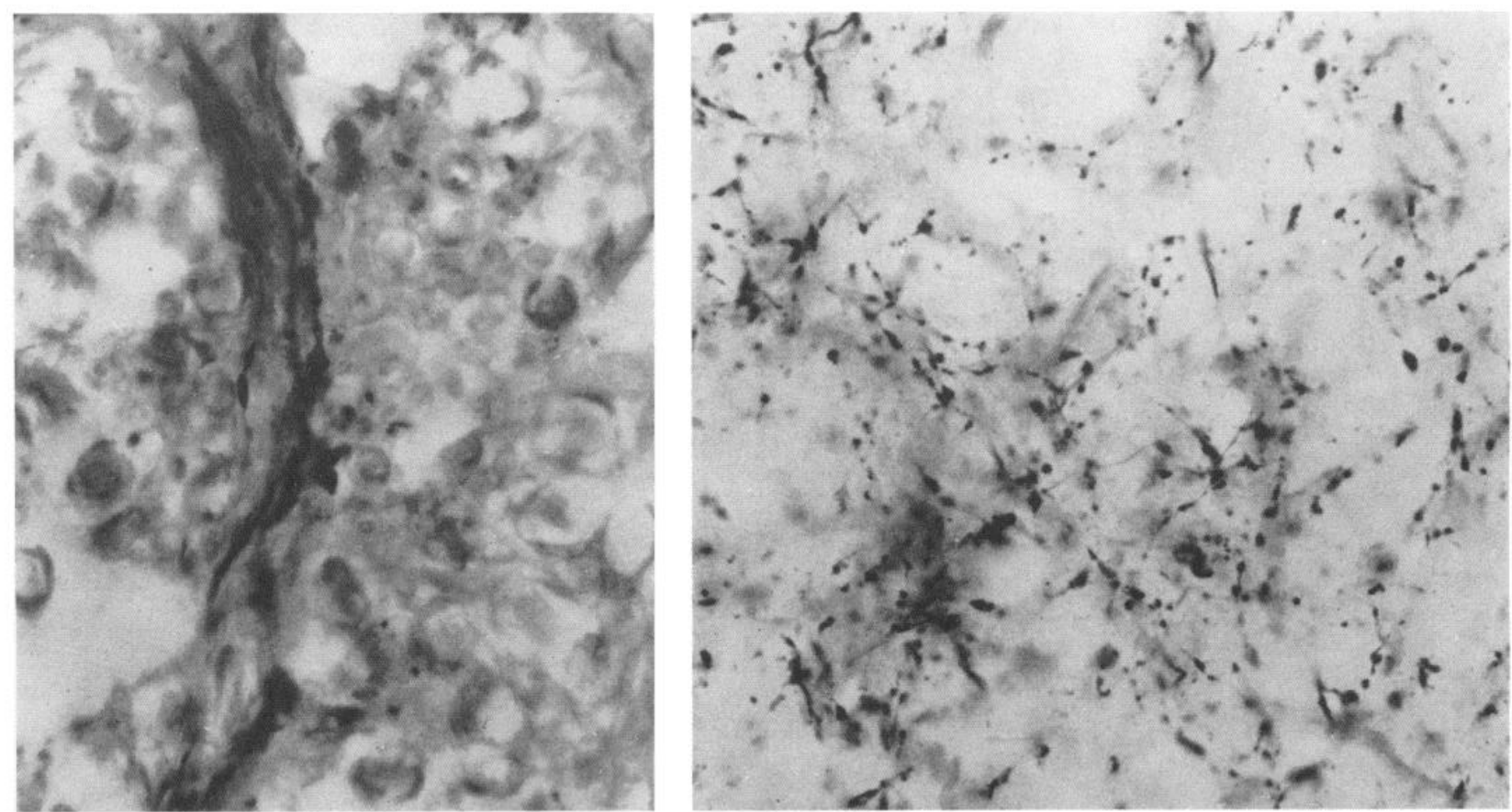

Figure 4. Two examples of selective black staining of degenerating axons by the suppressive Nauta-Gygax method (1954; here slightly modified as described by Nauta, 1957). Left, A slender fascicle of degenerating dorsal root fibers traversing the dorsal funiculus of the spinal cord of a cat killed $5 \mathrm{~d}$ following transection of a single dorsal root. Right, Profuse axon degeneration in layer IV of cat parietal cortex, $4 \mathrm{~d}$ after lesion of lateral thalamus. Note the droplike disintegration of fine preterminal axons encircling cell body from center toward upper left corner. Also note that none of the stained structures can be identified unequivocally as degenerating synaptic terminals. From Windle (1957), courtesy of Charles C Thomas (Springfield, IL).

our conclusion that, of a variety of organic acids we compared, citric acid was the best acidifier for fiber tracing, as it gave the sections a clear, translucent amber background.

The procedure at which we had now arrived (Nauta and Gygax, 1951) stained normal and degenerating fibers with equal intensity (Fig. 3). In a preliminary study of the rat fornix I found it difficult, and sometimes impossible, to trace dispersed degenerating fibers across regions densely filled with normal fibers. Therefore, I decided that it would be necessary to modify the procedure so that it would show degenerating fibers selectively.

In my search for selective visualization I was assisted by Lloyd Ryan, a major in the U.S. Air Force whom I met by chance at a party. Ryan was completing a doctoral dissertation in aerodynamics at the Federal Institute of Technology, and turned out to have a wide-ranging knowledge of the chemistry of photography. When I told him of my struggles with the Bielschowsky method, he exclaimed that its mechanisms must share many features with the photographic process. He asked if I had ever carried it out in the darkroom. No, I said, I hadn't. And so, following his suggestion, we treated sections under a dark red safety light and found that silver under these conditions stained degenerating fibers more intensely than normal fibers. This modification, however, by no means eliminated all staining of normal fibers, and since it also was very cumbersome to handle free-floating frozen sections in the darkroom, we decided that we needed some chemical alternative to the absence of light as differentiating factor in the silver staining of normal and degenerating fibers.

The search for such a chemical alternative was long and tedious. After months of trying combinations of virtually all mordants ever applied to brain tissue, we finally obtained the hoped-for effect by sequential pretreatment of the sections with potassium permanganate and potassium bisulfite (Nauta and Ryan, 1952). Using this method, and in collaboration with Verena Bucher, a neuroanatomist associated with the distinguished Zurich neurophysiologist W. R. Hess, I completed a charting of the efferent connections of the rat's visual cortex, but when I moved to the Walter Reed Army Institute of Research in Washington, DC, toward the end of 1951 , I was distressed to find that the permanganate-metabisulfite method didn't work there. I never did find out whether that failure was due to differences in the chemicals or in the rats I used in Zurich and Washington. Anyhow, it took the better part of my first year at Walter Reed to get the method to work again, by substituting a treatment with phosphomolybdic acid-later replaced by uranyl nitratefor the metabisulfite step. In this recovery project, once again, I was fortunate to be helped by Paul Gygax, who spent his first year in the United States in my laboratory at Walter Reed, before moving on to the DuPont Company.

Compared with the original, nonselective method, the selective silver technique we finally published (Nauta and Gygax, 1954) made it easy to trace degenerating axons over long distances and, in many cases at least, to identify the area of their termination (Fig. 4). As a consequence of that convenience, the "suppressive" method-as it later was often called-came to be used far more widely than its nonsuppressive parent method.

Convenient as the suppressive method may have been, it left some important questions of interpretation unanswered. For 


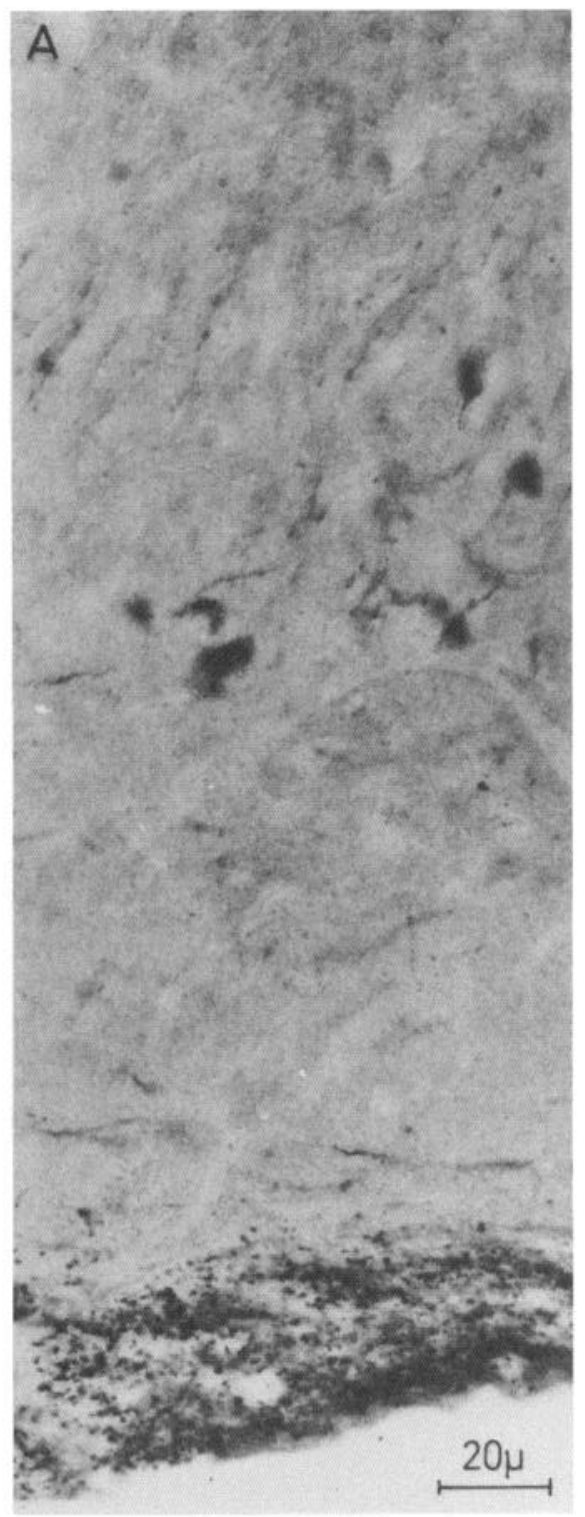

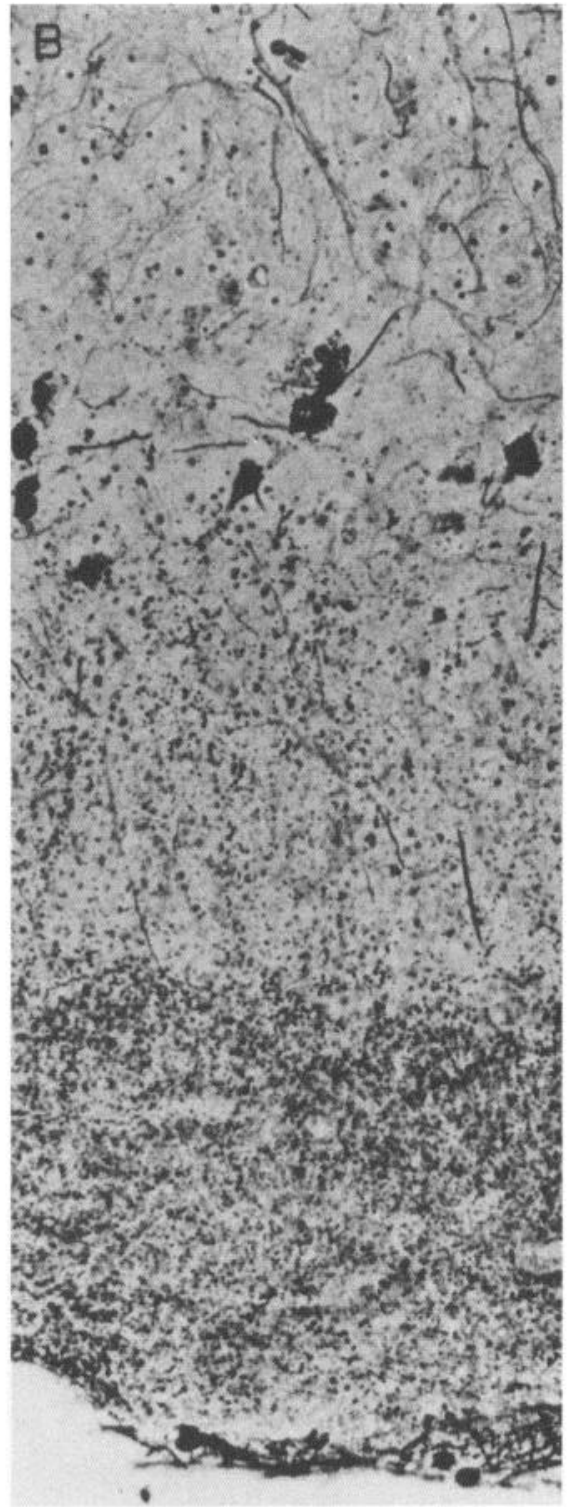

Figure 5. Degenerating olfactory tract fibers in the piriform (olfactory) cortex of a rat, $5 \mathrm{~d}$ after removal of the ipsilateral olfactory bulb. $A, \mathrm{~A}$ section stained by the suppressive Nauta-Gygax method shows axon degeneration only in the most superficial part of the plexiform layer. $B$, A slightly modified nonsuppressive Nauta-Gygax procedure demonstrates massive degeneration of axon terminals throughout the plexiform layer, particularly dense in the layer's superficial (lower) half. Much sparser terminal degeneration appears in the pyramidal and multiform cell layers appearing in the upper third of the photograph. From Heimer (1970a), courtesy of Springer Verlag (New York) instance, soon after its introduction, disagreements arose over the interpretation of images of fine-fiber degeneration appearing in the termination areas. Did the method bring out in such areas only the preterminal end-ramifications of degenerating axons, or were at least some of the stained structures actual axon terminals (see Fig. 4)? In retrospect, it seems obvious that this controversy could not be settled definitively by light microscopic methods alone, even though it should be added that the Bielschowsky-Gros method introduced by Szentágothai in the late 1930 s, and abandoned too early, might well have gone some way toward resolving the issue. As neuroanatomical methodology developed, degenerating boutons terminaux were not recognized in the electron microscope until nearly ten years later (see Guillery, 1970, for a brief review). Along with the axon terminals, their postsynaptic correspondents could be identified as well. By combining light and electron microscopic techniques, only then, in the early 1960 s, did it become possible to determine not only the distribution but also the mode of termination of degenerating fiber systems.

There were other problems connected with the "suppressive
Nauta-Gygax method." The most serious of these was that, as electron microscopy became more widely used, evidence appeared that the selectivity for degenerating fibers had been obtained at a cost. It now seemed that the pretreatment employed to suppress the staining of normal fibers also suppressed, though less drastically, the staining of the finer terminal ramifications of degenerating fibers.

This problem was forcefully brought to my attention in 1965 by Lennart Heimer when he joined us at the Massachusetts Institute of Technology - where I had moved the year beforeas a visiting associate from Göteborg. At Göteborg, Heimer had been tracing fiber pathways in the rat's olfactory system, and had noted that the terminal degeneration appearing in the piriform cortex following ablation of the olfactory bulb was brought out in very much higher density and greater detail by the nonsuppressive than by the suppressive Nauta-Gygax method (Fig. 5). At MIT, Heimer set out in quest of a procedure that would selectively stain degenerating axons without suppressing the staining of their terminals. Within a year, in collaboration with Robert Fink, he managed to develop not one, but two such 
Figure 6. Electron micrographs of degenerating axon terminals in the olfactory cortex, silver-stained by the FinkHeimer (1967) method. The procedure applied to obtain these photographs was as follows. (1) Frozen-cut sections, 25$30 \mu \mathrm{m}$ thick, were stained for axon degeneration, yielding images such as that shown in Figure $5 B$. (2) A small, carefully selected area of about $1 \mathrm{~mm}^{2}$ was excised from the stained section, refixed, mounted on an empty Epon base, and embedded flat in Epon. (3) The Epon slab so obtained was sectioned on an ultramicrotome, and the resulting ultrathin sections were examined and photographed in the electron microscope. Degenerating axon terminals $(d)$ are characterized by high electron opacity, hence their dark appearance, contrasting markedly with that of normal terminals ( $n$, near lower right corner of $B)$. While a very fine grain of metallic silver particles appears throughout the sections, note that heavier, coarsergrained silver deposits are limited to the dark profiles of the degenerating boutons terminaux. From Heimer (1970b), courtesy of Springer Verlag (New York).
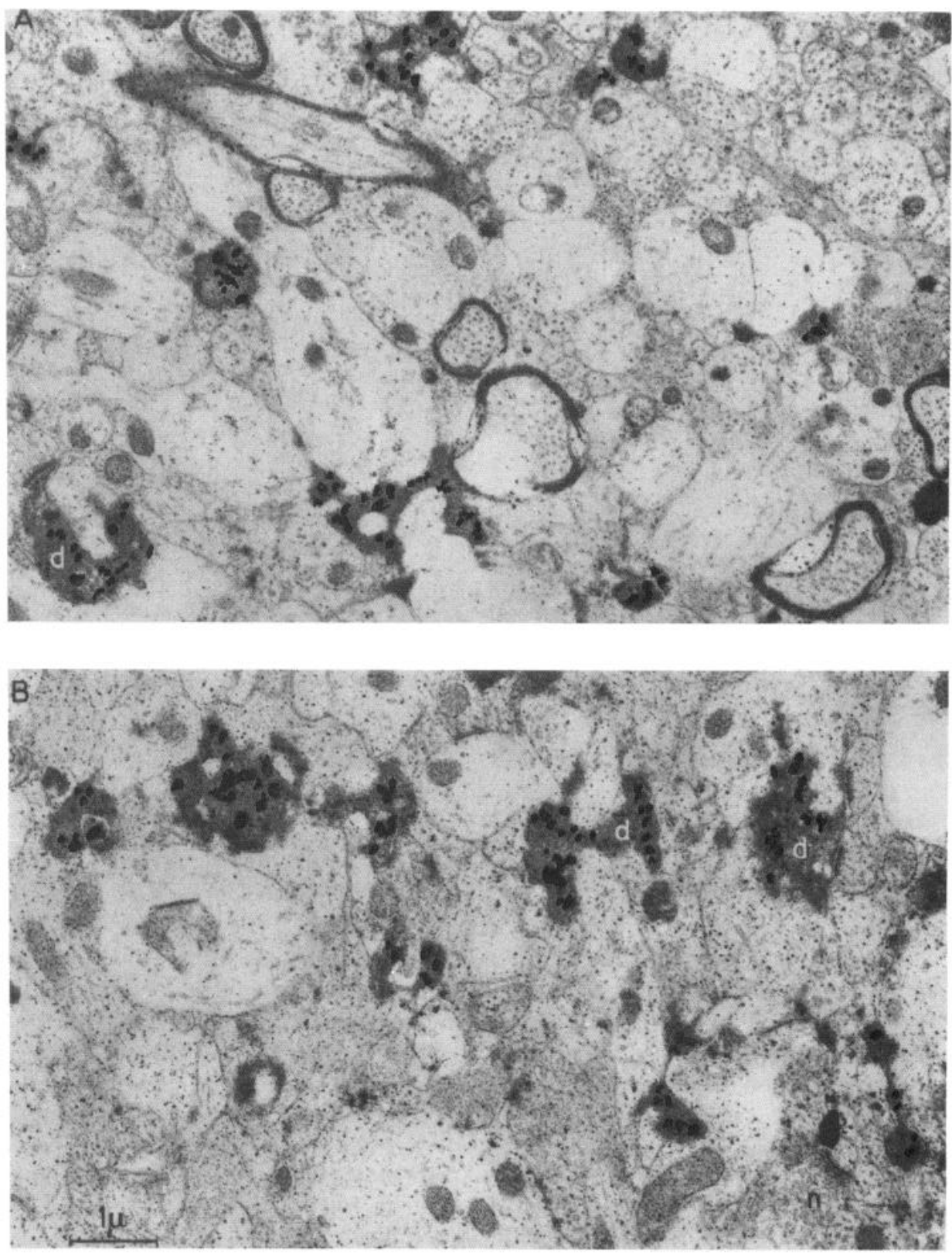

procedures. Remarkably, neither of these required the use of any chemical that had not already been used in the Nauta-Gygax methods. Rather, the main procedural variants were (1) application of potassium permanganate without previous treatment of the sections with phosphomolybdic acid or uranyl nitrate and (2) subsequent silver impregnation in a solution of silver nitrate mixed with either uranyl nitrate (procedure I) or pyridine (procedure II) (for a full discussion of these modifications see Heimer, 1970a).

In the piriform cortex of rats deprived of the ipsilateral olfactory bulb 3-5 d before death, the Fink-Heimer methods yielded pictures of abundant terminal degeneration entirely similar to that shown by Figure $5 B$. Comparable images appeared in the superior colliculus after contralateral eye enucleation, as well as in the distribution areas of the corpus callosum following hemidecortication, and in the hypothalamic distribution of the transected stria terminalis (cf. Heimer, 1970a).

When the two new methods were published (Fink and Hei- mer, 1967), however, they were received with much skepticism. Were those black, spheroidal particles they revealed as densely crowding the plexiform layer of the piriform cortex really silverstained degenerating boutons? Weren't there far too many of them, and didn't they look much more like the particles of a random silver precipitate? I must admit that I once had harbored the same doubts. Fifteen years earlier, while still working with the original, nonsuppressive silver method, I had often encountered such dense accumulations of silver particles, and had decided that they had to be mere random precipitates. I had been wrong, and Heimer (1970b) dispelled all doubts about that by providing electron microscopic evidence that the black particles in the piriform cortex were indeed silver-stained degenerating axon terminals (Fig. 6). Thereafter, the Fink-Heimer procedures became the methods of choice for tracing degenerating fibers in the central nervous system.

In spite of their promise, the Fink-Heimer methods were destined to compose a brief last chapter in the 90 -year-long 
history of tracing fiber pathways by means of experimentally induced Wallerian degeneration. By the time the methods were coming into wide use, Maxwell Cowan, Anita Hendrickson, and their associates (Cowan et al., 1972) were already adapting for routine use the fundamentally different strategy, introduced by Lasek et al. (1968), of tracing nerve fibers by autoradiographic recording of the uptake and intra-axonal transport of radioactively labeled amino acids. This strategy offered enough advantages to replace the Wallerian degeneration methods almost completely. A few years later, nerve fiber tracing methods based on the detection of intra-axonal transport of horseradish peroxidase and of plant lectins (Gerfen and Sawchenko, 1984) enriched the neuroanatomical arsenal still further. Today, the student entering the field of neuroscience encounters a wealth of fiber tracing methods, some purely anatomical, others selectively histochemical in nature, that can aid in the conceptual unraveling of the brain's complexity. As an observer of the present-day scene, I sometimes find it difficult to remember that I once was part of a past scene where there was only the Marchi method to which one could resort for the anterogradc tracing of axonal connections in the central nervous system.

\section{References}

Auerbach L (1899) Das terminale Nervennetz in seinen Beziehungen zu den Ganglienzellen der Zentralorgane. Mschr Psychiatr Neurol 6:192-214.

Barr M (1939) Some observations on the morphology of the synapse in the cat's spinal cord. J Anat 74:1-11.

Bielschowsky M (1904) Die Silberimprägnation der Neurofibrillen. J Psychol Neurol 3:169-189.

Bodian D (1936) A new method for staining nerve fibers and nerve endings in mounted paraffin sections. Anat Rec 65:89-97.

Cajal SR (1904) Ùeber einige Methoden der Silberimprägnierung zur Untersuchung der Neurofibrillen, der Achsenzylinder und derer Endverzweigungen. $Z$ Wissenschaftl Mikrosk 20:401-408.

Cajal SR (1909) Histologie du système nerveux de l'homme et des vertébrés, Tome I, p 74. Paris: Maloine.

Cajal SR (1935) Die Neuronenlehre. In: Bumke-Foerster Handbuch der Neurologie, Vol I, pp 887-1027. Berlin: Springer.

Cowan WM, Gottlieb DI, Hendrickson AE, Price JL, Woolsey TA

(1972) The autoradiographic demonstration of axonal connections in the central nervous system. Brain Res 37:21-51.

Dempsey EW (1957) New methods versus old. In: New research techniques of neuroanatomy (Windle WF, ed), pp 76-78. Springfield, IL: Thomas.

Fink RP, Heimer L (1967) Two methods for selective silver impregnation of degenerating axons and their synaptic endings in the central nervous system. Brain Res 4:369-374.

Gerfen CR, Sawchenko PE (1984) An anterograde neuroanatomical tracing method that shows the detailed morphology of neurons, their axons and terminals: immunohistochemical localization of an axonally transported plant lectin, Phaseolus vulgaris-leucoagglutinin (PHA-L). Brain Res 290:219-238.

Gibson WC (1937) Degeneration of the boutons terminaux in the spinal cord. Arch Neurol Psychiatry (Chicago) 38:1145-1157.

Glees $P$ (1946) Terminal degeneration within the central nervous sys- tem as studied by a new silver method. J Neuropathol Exp Neurol 5:54-59.

Guillery RW (1970) Light- and electron-microscopical studies of normal and degenerating axons. In: Contemporary research methods in neuroanatomy (Nauta WJH, Ebbesson SOE, eds), pp 77-105. New York: Springer.

Heimer L (1970a) Selective silver-impregnation of degenerating axoplasm. In: Contemporary research methods in neuroanatomy (Nauta WJH, Ebbesson SOE, eds), pp 106-131. New York: Springer.

Heimer L (1970b) Bridging the gap between light and electron microscopy in the experimental tracing of fiber connections. In: Contemporary research methods in neuroanatomy (Nauta WJH, Ebbesson SOE, eds), pp 162-172. New York: Springer.

Held H (1897) Beiträge zur Struktur der Nervenzellen und ihrer Fortsätze. $2^{c}$ und $3^{c}$ Mitteilung. Arch Anat Physiol Lpz Anat Abt 204 294.

Hoff EC (1932) Central nerve terminals in the mammalian spinal cord and their examination by experimental degeneration. Proc R Soc Lond [Biol] 3:175-188.

Lasek R, Joseph BS, Whitlock DG (1968) Evaluation of a radioautographic neuroanatomical tracing method. Brain Res 8:319-336.

Marchi V, Algeri G (1885) Sulle degenerazioni descendenti consecutive a lesioni sperimentale in diverse zone della corteccia cerebrale. Riv Freniat 11:492-494

Minckler J (1940) The morphology of the nerve terminals of the human spinal cord as seen in black silver preparations, with estimates of the total number per cell. Anat Rec 77:9-25.

Nauta WJH (1957) Silver impregnation of degenerating axons. In: New research techniques of neuroanatomy (Windle WF, ed), pp 17 26. Springfield, IL: Thomas.

Nauta WJH, Bucher VM (1954) Efferent connections of the striate cortex in the albino rat. J Comp Neurol 100:257-286.

Nauta WJH, Gygax PA (1951) Silver impregnation of degenerating axon terminals in the central nervous system: (1) technic, (2) chemical notes. Stain Technol 26:5-11.

Nauta WJH, Gygax PA (1954) Silver impregnation of degenerating axons in the central nervous system: a modified technique. Stain Technol 29:91-93

Nauta WJH, Ryan LF (1952) Selective silver impregnation of degenerating axons in the central nervous system. Stain Technol 27:175179.

Nauta WJH, van Straaten JJ (1947) The primary optic centres in the rat. An experimental study by the "bouton" method. J Anat 81:127134.

Phalen GS, Davenport HA (1937) Pericellular end bulbs in the central nervous system of vertebrates. J Comp Neurol 68:67-82.

Rasdolsky J (1925) Beiträge zur Architektur der grauen Substanz des Rückenmarks (Unter Benutzung einer neuen Methode der Färbung der Nervenfaserkollateralen). Virchows Arch [Pathol Anat] 257:356363.

Schimert J (1938) Die Endigungsweise des Traktus vestibulospinalis. Z Anat Entwicklungsgesch 108:761-767.

Schimert J (1939) Das Verhalten der Hinterwurzelkollateralen im Rückenmark. Z Anat Entwicklungsgesch 109:665-687.

Szentágothai-Schimert J (1941) Die Endigungsweise der absteigenden Rückenmarksbahnen. Z Anat Entwicklungsgesch 111:322-330.

Vogt O (1898) Sur un faisceau septo-thalamique. C R Soc Biol 50: 207-208.

Windle WF, ed (1957) New research techniques of neuroanatomy. Springfield, IL: Thomas. 